\title{
A Diachronic Analysis of Self-Mention and Its Rhetorical Functions in Academic Writing across Four Disciplines
}

\author{
Hongyu Tao \\ School of Foreign Languages, Southeast University, Nanjing, China \\ Email: taohongyu1997@163.com
}

How to cite this paper: Tao, H. Y. (2021). A Diachronic Analysis of Self-Mention and Its Rhetorical Functions in Academic Writing across Four Disciplines. Open Journal of Social Sciences, 9, 118-134. https://doi.org/10.4236/jss.2021.97008

Received: June 14, 2021

Accepted: July 13, 2021

Published: July 16, 2021

Copyright $\odot 2021$ by author(s) and Scientific Research Publishing Inc. This work is licensed under the Creative Commons Attribution International License (CC BY 4.0).

http://creativecommons.org/licenses/by/4.0/

\section{(c) (i) Open Access}

\begin{abstract}
In recent decades, self-mention expressions which explicitly show academic writers' participation in the research process have yielded a lot of attention. Substantial studies have explored the cross-cultural and interdisciplinary differences in the use of self-mention, yet few studies have been conducted on the diachronic changes in frequency of self-mention in academic writing. Based on Walková's classification of the rhetorical functions of self-mention personal pronouns, the authors investigated the interdisciplinary disparities and diachronic changes of the deployment of rhetorical functions of self-mention personal pronouns. The disciplines explored in this paper are applied linguistics, sociology, electronic engineering and biochemistry \& molecular biology. By investigating the use of first person pronouns I, we, me, us and determiners my, our in 108 research articles published over the past 40 years, this study shows that applied linguistics is the only discipline that has seen a decline in the use of first person pronouns. The chi-square analysis also indicates that there is a significant difference in the use of rhetorical functions among the four disciplines.
\end{abstract}

\section{Keywords}

Self-Mention, Rhetorical Function, Diachronic Analysis, Interdisciplinary

Differences

\section{Introduction}

Self-mention, described as the extent of author presence in academic discourse, is a topic that has received much attention in academic writing in recent decades (e.g. Ivanič, 1998; Kuo, 1999; Tang \& John, 1999; Hyland, 2002; Harwood, 2005). 
It plays a vital role in accentuating the writer's contribution to the academic community and promoting the interaction between the author(s) and the readers. Also, presenting a discoursal self is central to the writing process (Ivanič, 1998).

Traditionally, academic writing has been viewed as a type of discourse expressing depersonalized and objective information. Many scholars believe that it should be presented as if human agency is not part of the writing process. As a result, many academic writers tend to alienate themselves from the presentation of their research findings and avoid employing personal pronouns in their research papers (Harwood, 2005). However, with the ever-increasing number of research conducted each year, it becomes harder and harder for researchers to catch attention in this academic environment. Against this backdrop, some scholars claim that it is of necessity for writers to promote themselves and outline their novel contribution to their discipline. Meanwhile, as the rhetorical functions of self-mention expressions gain increasing attention in the academic field, the use of these expressions has been increasingly advocated. Hyland (2002) mentions that first person pronouns are a powerful means by which writers express an identity by asserting their claim to speak as an authority. They are valuable rhetorical strategies which can help construct a credible image for academic writers. Hence, the notion of writer presence in academic writing has been a focus of interest for many researchers.

A bunch of researchers have studied the differences of authorial presence among different sections within one paper, among soft and hard disciplines and across cultures (e.g. Harwood, 2005; Ivanič \& Camps, 2001; Lee, 2013; Dueñas, 2007). However, there seems to be a dearth of research on diachronic changes of self-mention in the past several decades in English academic writing. Therefore, the current study aims at discovering the changes in the use of self-mention personal pronouns over time.

\section{Literature Review}

\subsection{Self-Mention in Academic Writing across Disciplines}

Academic writing, which not only conveys disciplinary "content" but also carries a representation of the writer, is an act of identity (Hyland, 2002). In research articles, authors use self-mention expressions to make themselves visible and meanwhile construct their relationship with readers and with their discourse community (Kuo, 1999). Such explicit authorial presence is realized through the use of first-person pronouns (e.g., I, we), possessive determiners (e.g., my, our) and third-person nominal phrases (e.g., the author). Among them, the most visible and powerful manifestation of authorial identity is the use of first person pronouns and their corresponding determiners (e.g. Hyland, 2001; Ivanič, 1998).

Not all academic communities employ the same conventions and readers in different fields have different expectations and norms of argument. A great deal of research claims that writers of various disciplines use self-mention in diverse 
ways and the differences between soft sciences and hard sciences are especially salient.

A substantial body of researchers found that writers in soft sciences employ more personal pronouns in academic writing than those in hard disciplines. According to Hyland (2001), much more frequent use of self-reference occurred in soft disciplines such as applied linguistics and sociology than in hard ones like computer science and electronic engineering. He further supplemented this standpoint by stating that $69 \%$ of all cases of self-mention were in the humanities and social science papers, with an average of 38 per article, compared with only 17 per paper in science and engineering (Hyland, 2008). Some other studies have the consistent results. Mirzapour (2016) demonstrated that writers in applied linguistics tended to make extensive use of first person plural pronouns in their research articles, compared with their counterparts in chemistry. In the same line but more specifically, Li and Lee (2013) discovered that first person singular pronoun I occurred more frequently in soft disciplines (humanities/social sciences) than in hard disciplines (natural science).

However, these seemingly "robust" results have discrepancies in a recent work. Hyland \& Jiang (2018) discovered that papers in electrical engineering (85.8 per 10,000 words) employed more self-mention markers than in applied linguistics (68.4 per 10,000 words) published in 2015. This finding is very surprising since it refutes most of the related studies which investigate the differences between soft and hard sciences in the employment of self-mention.

From the aforementioned studies, we can find that there are divergences in interdisciplinary differences of the frequency of self-mention expressions. More specifically, there is no consensus about whether the soft or hard ends of the scientific spectrum employ more self-mention in academic discourse. Thus, further investigation into the interdisciplinary differences in the use of self-mention personal pronouns is necessary.

\subsection{Diachronic Changes of Self-Mention in Academic Writing}

In the 1980s, academic writing was supposed to be objective and impersonal. This genre requirement was explicitly demonstrated in many academic writing manuals and textbooks, and reflected in published papers. Lachowicz (1981) held that impersonality emphasizes objectivity, open-mindedness and the established factual nature of a given activity and that it functions to underline the common share of knowledge with the community and stresses the collective responsibility of academic endeavor. According to Arnaudet and Barrett (1984), authors should try their best to eliminate first person pronouns from their academic writings. However, as time went on, there has been a shift to a more subjective mode of academic writing which exploits personal pronouns for negotiating the writer-reader relationship and construing an authorial voice in the last three decades (Dontcheva-Navrátilová, 2013). Furthermore, the author pinpoints that such tendency towards a higher degree of subjectivity is especially 
remarkable in soft sciences. In contrast to this, the corpus analysis by Hyland \& Jiang (2018) suggests that applied linguistics has seen a reduction in the use of first person pronouns during the past 50 years, while in sociology, biology and electronic engineering, the frequency has increased considerably. Apparently, there is contradiction between these two studies in the diachronic changes of self-mention in academic writing in applied linguistics. In addition, the differences between soft and hard disciplines in terms of the use of self-mentions have also not been thoroughly discovered. This sharp contrast indicates that a further diachronic study of the change in the use of self-mention is of necessity.

\subsection{Rhetorical Functions of Self-Mention in Academic Writing}

The extensive existing research has identified that self-mention plays a range of rhetorical functions which strategically project the authors' positioning with respect to their research, to the potential readers, to their academic community and so on. Several taxonomies for such roles have been proposed (Tang \& John, 1999; Hyland, 2002; Luzon, 2009; Walková, 2019). Among these taxonomies, the one put forward by Walková is very concise and comprehensive. More importantly, it is the most suitable for the current study which focuses on reader-exclusive first person pronouns in research articles by experienced scientific writers.

Walková (2019) proposes that the power of self-mention has three dimensions, namely rhetorical functions, grammatical forms, and hedging/boosting in its co-text. It is the first dimension (rhetorical functions of self-mention) that we are concerned in the current study. She took Hyland (2002) taxonomy as a starting point for its clarity and focused on reader-exclusive pronouns and then proposed five rhetorical functions of reader-exclusive first person pronouns, as shown in Table 1.

These five rhetorical functions can be seen as reflecting a continuum from the highest to the lowest degree of authority. That is, the first function of self-mention (i.e. stating one's original contribution to the field by stating results and finding) is the most powerful and face-threatening.

Since there are differences in the frequency of self-mention across disciplines, we hypothesize that writers in each discipline also differ in their employment of the five rhetorical functions of self-mention. In addition, there is a paucity of

Table 1. Rhetorical functions.

\begin{tabular}{cr}
\hline Functions & Rhetorical functions \\
\hline Function 1 & Stating one's original contribution to the field by stating results and findings. \\
Function 2 & Elaborating an argument, presenting an opinion, or stating knowledge. \\
Function 3 & Describing or explaining a research decision or procedure. \\
Function 4 & Stating a purpose, intention or focus. \\
Function 5 & Acknowledging other researchers. \\
\hline
\end{tabular}


empirical investigations into the diachronic change of rhetorical functions. Therefore, the gap in the literature we aim to fill through this study is the exploration of the cross-disciplinary disparities and diachronic changes in the frequency of self-mention personal pronouns and their rhetorical functions in academic text. The four research questions are as follows:

1) What are the interdisciplinary differences in self-mention expressions?

2) What are the diachronic changes in the use of self-mention in each discipline?

3) What are the interdisciplinary differences in terms of rhetorical functions?

4) What are the diachronic changes in the frequency of the five rhetorical functions?

\section{Method and Corpus}

\subsection{Disciplines and Journals Selection}

Becher (1989) divides the academy into soft and hard fields. Specifically, the hard fields are defined as the natural (and mathematical) sciences, while the soft fields are defined as the humanities and social sciences. Following Becher's taxonomy of the disciplines, we chose applied linguistics (AL) and sociology (S) as representatives of soft sciences, and electronic engineering (EE) and biochemistry \& molecular biology (BMB) as hard sciences. To ensure the reliability of the data, the authors selected articles from 12 journals ( 3 journals in each discipline) that achieved the top ranking in their fields according to the impact factor in 2015. The journals are listed in Appendix 1.

The authors established a corpus by randomly extracting 3 research articles from each journal respectively at three time points over the past 40 years: 1975, 1995, and 2015. All selected articles were review articles and empirical studies. Therefore, the study was doubly comparative, that is, comparison was made along the axes of decades and disciplines.

The papers were firstly converted from PDF format to Text format using AntFile Converter (Anthony, 2017). For all the selected articles, only so-called body-parts were investigated in the current study. That is to say, titles, abstracts, lists of keywords, figures, tables, appendices and references were excluded. However, the acknowledgements were retained since the model employed by the current study includes the function of acknowledging other researchers. Hence, the corpus comprised 108 papers of 767,047 words in total (see Table 2). Then,

Table 2. Corpus size and composition.

\begin{tabular}{ccccc}
\hline Corpus & 1975 & 1995 & 2015 & Overall \\
\hline AL & 42,825 & 54,001 & 82,701 & 179,527 \\
S & 50,877 & 65,637 & 61,443 & 177,957 \\
BMB & 44,012 & 65,317 & 58,520 & 167,849 \\
EE & 69,230 & 79,146 & 93,338 & 241,714 \\
Total & 206,944 & 264,101 & 296,002 & 767,047 \\
\hline
\end{tabular}


expressions of authorial presence were searched in each article using AntConc concordance software (Anthony, 2019). The items searched were the first person pronouns I, we, me, us and determiners my, our.

\subsection{Exclusion of Reader-Inclusive Occurrences}

In addition, to ensure the relevance of the data, we also manually analyzed those searched items one by one in context in order to ensure that all of them referred to the author(s). Items that did not refer to the author(s) (for instance, those found in direct quotations from participants) were not counted as the occurrences (e.g. example (1)). More importantly, only reader-exclusive first person uses were retained as valid occurrences. Some of the first person plural pronouns in those articles were very confusing (see example (2) and (3)) because it is hard to tell whether they are reader-inclusive or reader-exclusive.

Examples:

1) And we will then analyze what's an essay, what's a reflection, what's an opinion paper.

(AL, 2015)

2) In the American context, for example, we have no adequate sociological paradigm that facilitates the classification and study of such organizational entities as health sciences centers, prepaid group practices, comprehensive medical foundations, hospital mergers, and the like.

3) Our work indicates that cellular compartmentalization confines transcriptional noise to the nucleus, thereby preventing it from interfering with the control of single-cell transcript abundance in the cytoplasm.

(BMB, 2015)

Example (1) was collected from the interview and here we refer to the participants rather than the author.

In example (2), we is a general use and it refers to the audience of the paper and the author(s), so it is reader inclusive and is excluded from occurrences. According to Luzon (2009), the reader-inclusive personal pronouns are mostly used while assuming shared knowledge, goals and beliefs. In contrast, in example (3), our refers only to the authors of the research article. So only such reader-exclusive occurrences were included in the present study.

Collaboration and teamwork are typical of academic research. Due to the difficulties in collecting enough single-authored articles in biology and electronic engineering (most research articles in the two disciplines are multi-authored), especially in 1975 and 1995, the authors did not take into account the differences between single or multiple authorship. Also, the current study focused on the functions and frequency of first person pronouns rather than the impact of single or multiple authorship on the use of self-mentions. Moreover, only one article written by the specific author(s) was included in the corpus so that we can eliminate the influence of writer's personal writing style on the results. 


\subsection{Classification of Self-Mention Occurrences}

After the quantitative examination of self-mention occurrences, the authors investigated each instance in the wider context in which it was used to determine its rhetorical function. While assigning the functional categories, we adopted the first dimension of the three-dimensional model of self-mention which has been mentioned above (Walková, 2019). In her opinion, personal self-mentions in academic discourse mainly perform five rhetorical functions. However, in some cases it is not easy to clearly state which function self-mentions perform because personal pronouns may serve more than one function at the same time and they are sometimes multifunctional (Vladimirou, 2007). In this case, categorizing the personal pronouns according to their primary function is a decent solution (Vladimirou, 2007). For instance, in example (4), it seems that we perform two types of rhetorical functions: One is stating the focus of this section and it involves forward signposting, the other is describing the research decision. The author categorized we in this sentence as "stating the focus of this section" (the fourth rhetorical function in the model) because it is the primary function it performs.

4) In this section we examine how firms and economic transactions are organized across a number of societies in order to assess how well various theories of corporate organization can account for these differences.

\section{Results and Discussion}

In this section, the results of this corpus-based study will be presented. By comparing the findings of the current study with those of previous studies, we will be able to analyze the potential causes of the similarities and differences between them.

\subsection{Diachronic Change and Interdisciplinary Differences in Frequency of Self-Mention in Four Disciplines}

This section tries to answer the first and second research questions by investigating the diachronic change and interdisciplinary differences of self-mention personal pronouns and then providing some explanations for the findings in light of other related previous studies.

As summarized in Table 3, frequency of self-mention personal pronouns varies with year and discipline. The average frequency in soft disciplines shows a slight decrease during the period, while in hard sciences the frequency has increased dramatically. To make the diachronic changes more pronounced, we also provide Figure 1. The raw data were normalized to frequency per 10,000 words to allow comparison across disciplines in different years.

There are both similarities and divergences between the current study and earlier studies in terms of the changing patterns of frequency of self-mention personal pronouns. The extant research substantiated that self-mention has been 


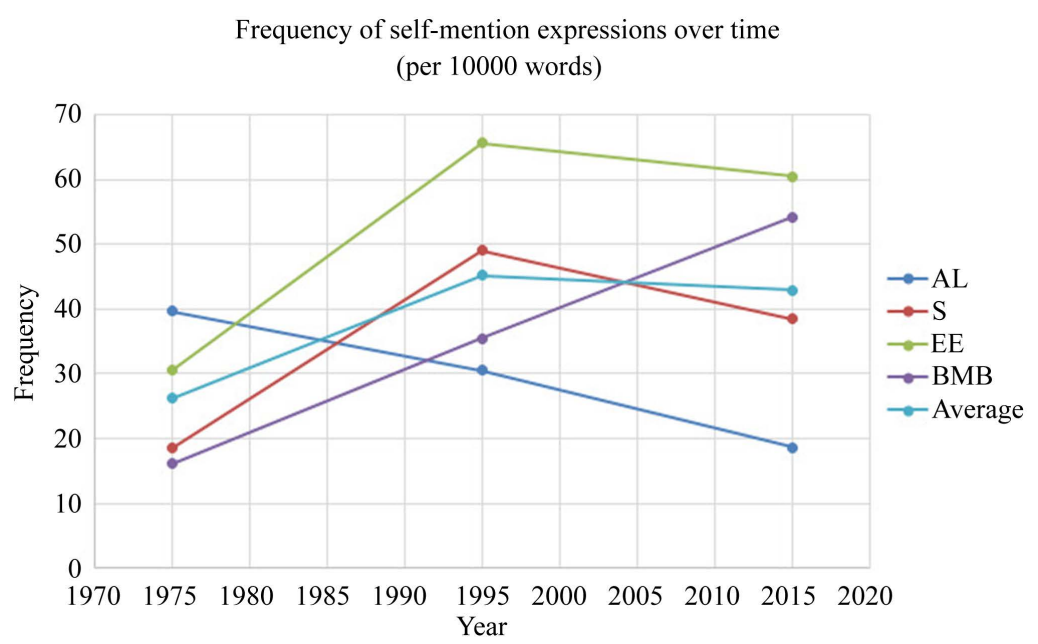

Figure 1. Diachronic change in frequency of self-mention expressions.

Table 3. Diachronic change in frequency of self-mention expressions (per 10,000 words).

\begin{tabular}{ccccc}
\hline Discipline & 1975 & 1995 & 2015 & Change (\%) \\
\hline AL & 39.70 & 30.55 & 18.62 & $-53 \%$ \\
S & 18.48 & 49.06 & 38.41 & $+108 \%$ \\
Average of soft disciplines & 29.09 & 39.81 & 28.52 & $-2 \%$ \\
EE & 30.48 & 65.70 & 60.43 & $+98 \%$ \\
BMB & 16.13 & 35.52 & 54.20 & $+236 \%$ \\
Average of hard disciplines & 23.31 & 50.61 & 57.32 & $+146 \%$ \\
Average of four disciplines & 26.20 & 45.21 & 42.92 & $+64 \%$ \\
\hline
\end{tabular}

increasingly advocated in recent decades (Dontcheva-Navrátilová, 2013). Many other scholars who are in favor of the use of first-person pronouns in research articles have gradually proved that they establish "a claim for recognition for academic priority" (Hyland, 2001; Martinez, 2005). The present study has confirmed results from some earlier research in that there is an overall increase (64\% growth) in the average frequency of self-mention markers in the four disciplines during this period.

The data from electronic engineering (+98\%), sociology (+108\%) and biochemistry \& molecular biology $(+236 \%)$ have all registered substantial increases, suggesting that writers in these fields have become more active in making a personal standing in their texts. Interestingly, the frequencies of first person pronouns in these three disciplines were the highest in 1995, as reported in Figure 1 . Wu (2010) argues that the 1980s witnessed people's increasing awareness of the important role of social context in the composing process. During this period, Social Theory of Discourse which combines language with social context and proposes that discourse is shaped and constrained by social structure was created (Fairclough, 1992). The "social" view of writing demonstrates that managing social relationship between the writer and the reader is crucial. Conse- 
quently, it is highly possible that the establishment of this theory leads to academic writers' raising awareness of the importance of the writer-reader interaction and then results in the increase in self-mention in academic discourse.

However, the growing trends are not uniform across disciplines. Applied linguistics has seen 53\% drop in the use of first person pronouns during the period, suggesting that writers in this field are now taking a more objective stance towards their research and seeking to downplay their personal roles. This interdisciplinary difference is in line with that from Hyland \& Jiang (2018). In their data, the frequency of self-mention expressions increased in biology $(+163 \%)$, electrical engineering $(+63 \%)$ and sociology $(+38 \%)$ but decreased in applied linguistics (-27\%) between 1965 and 2015. The reduction of self-mention in this field over time may be attributable to its shifting conventions. As explained by Hyland \& Jiang (2018), applied linguistics was a relatively young discipline with an undeveloped literature in the 1970s. During that period, a greater focus in this field was on personal accounts of language teaching, so the applied linguists' deployment of self-mentions was relatively high. Nevertheless, the increasing number of empirical studies and the broadening of the discipline to cover a wider range of topics in recent decades have led to the tremendous changes in how claims are argued and accepted in this field.

\subsection{Rhetorical Functions of Self-Mention}

This section will attempt to address the third and fourth research questions by making a qualitative analysis of the frequencies of the five rhetorical functions respectively.

Table 4 provides details of the frequency of rhetorical functions normalized to 10,000 words in each discipline respectively at the three time points. It is clear from Table 4 that the frequencies of these five functions are quite different in each discipline over the period. Additionally, the frequencies of the same rhetorical function at three time points are also differing. Furthermore, interdisciplinary differences in terms of the frequency of rhetorical functions of self-mention cannot be neglected. Nevertheless, it is difficult to tell whether such differences among the four disciplines are significant. Therefore, the authors also conducted

Table 4. Frequency of rhetorical functions of self-mention (per 10,000 words).

\begin{tabular}{ccccccccccccccc}
\hline $\begin{array}{c}\text { Rhetorical } \\
\text { functions }\end{array}$ & \multicolumn{3}{c}{ AL } & \multicolumn{3}{c}{ S } & \multicolumn{3}{c}{ S } & \multicolumn{3}{c}{ BMB } & \multicolumn{3}{c}{ EE } \\
\cline { 2 - 13 } & 1975 & 1995 & 2015 & 1975 & 1995 & 2015 & 1975 & 1995 & 2015 & 1975 & 1995 & 2015 \\
\hline Function 1 & 3.74 & 2.96 & 1.81 & 5.11 & 9.45 & 5.70 & 2.95 & 5.82 & 9.57 & 2.31 & 5.43 & 4.61 \\
Function 2 & 10.51 & 4.63 & 4.96 & 6.88 & 9.75 & 6.51 & 1.14 & 7.65 & 5.81 & 6.93 & 9.86 & 11.14 \\
Function 3 & 11.91 & 19.07 & 8.10 & 3.54 & 22.85 & 18.88 & 7.73 & 12.25 & 33.83 & 17.91 & 44.60 & 34.93 \\
Function 4 & 13.08 & 1.48 & 1.93 & 2.56 & 4.72 & 4.23 & 2.73 & 6.89 & 3.42 & 2.74 & 5.69 & 9.64 \\
Function 5 & 0.47 & 2.41 & 1.81 & 0.39 & 2.29 & 3.09 & 1.59 & 2.91 & 1.54 & 0.58 & 0.13 & 0.11 \\
Total & 39.71 & 30.55 & 18.61 & 18.48 & 49.06 & 38.41 & 16.14 & 35.52 & 54.17 & 30.47 & 65.71 & 60.43 \\
\hline
\end{tabular}


chi-square tests on the raw data of the frequency (i.e. absolute frequency) by using the software SPSS.

Table 5 shows the statistical result of chi-square tests in 1975, 1995 and 2015. As suggested by the results, the differences among the four disciplines in the employment of rhetorical functions of self-mention were all significant at each time point. The salient cross-disciplinary differences indicate that writers in these four disciplines exploit rhetorical functions of self-mention personal pronouns quite differently during the period.

Besides, in order to make the interdisciplinary disparities more salient, the authors also provide three figures which are based on the raw data of the frequency (i.e. absolute frequency) of the five rhetorical functions. As shown below, Figures 2-4 respectively present the result for the frequencies in 1975, 1995 and 2015.

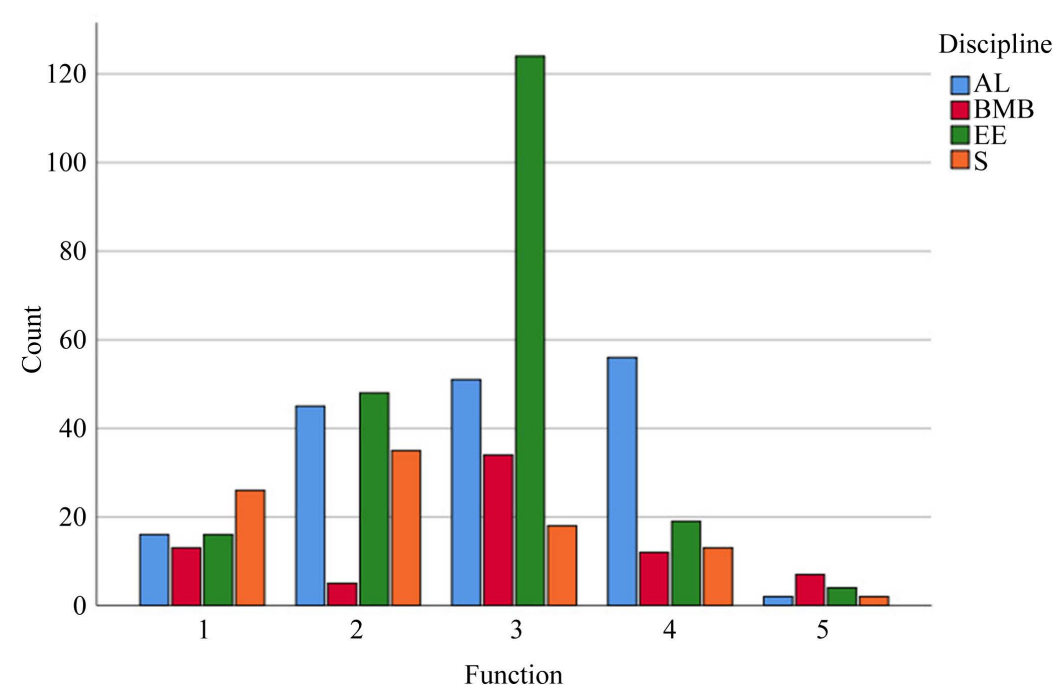

Figure 2. Frequency of rhetorical functions in 1975.

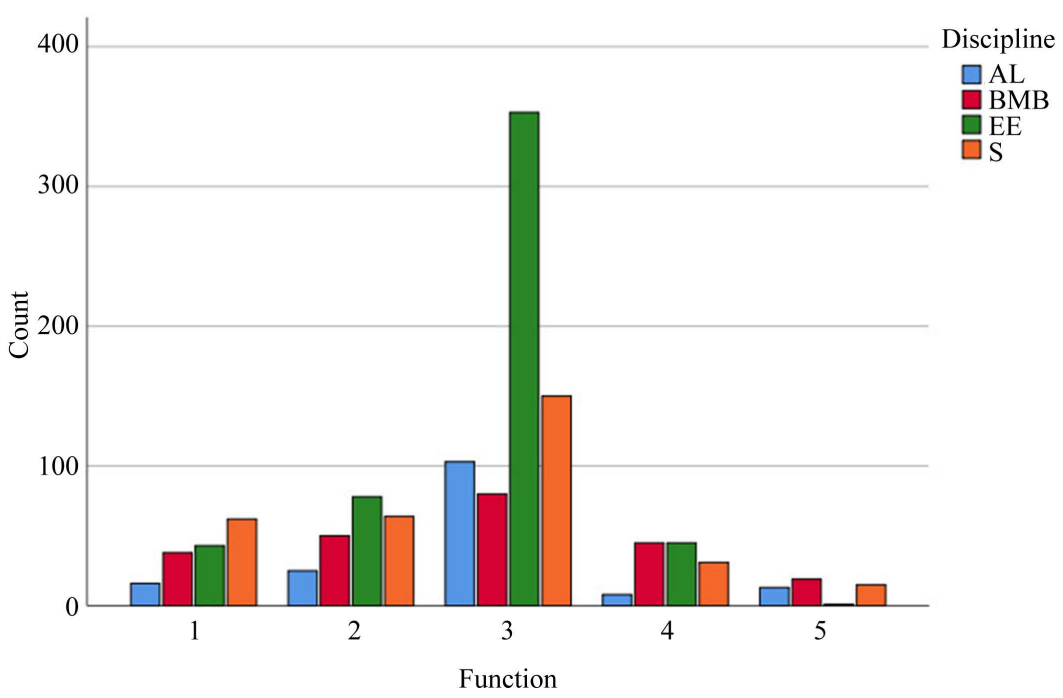

Figure 3. Frequency of rhetorical functions in 1995. 


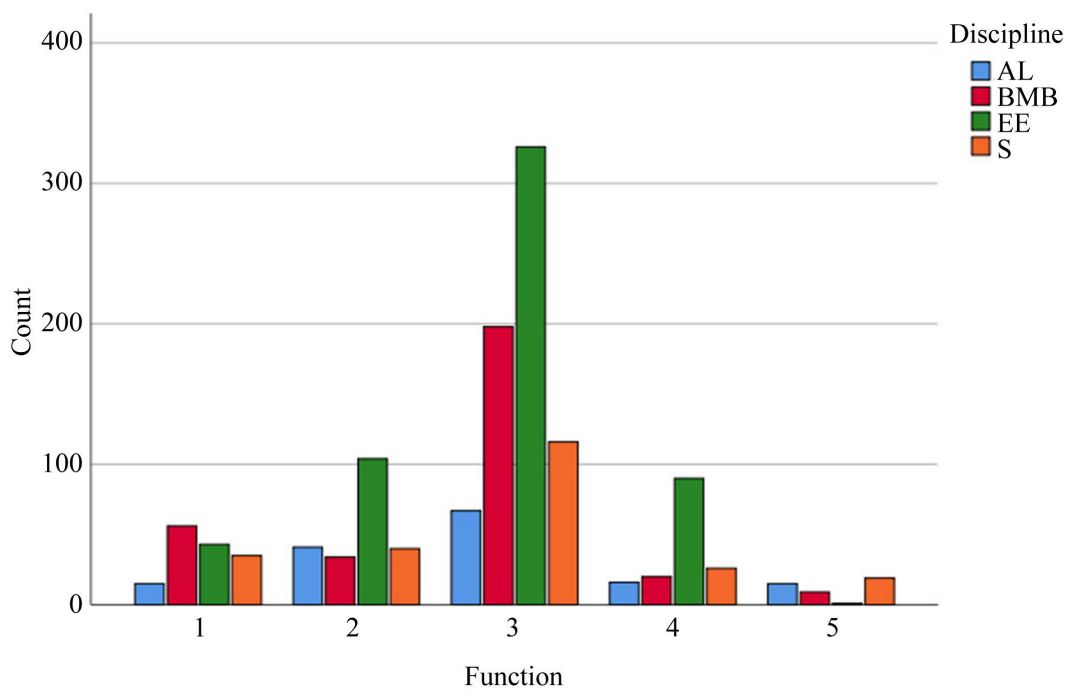

Figure 4. Frequency of rhetorical functions in 2015.

Table 5. Chi-square tests for the frequency of rhetorical functions in 1975, 1995 and 2015.

\begin{tabular}{ccccc}
\hline Year & $X^{2}$ & $\mathrm{df}$ & $p$ Value & Effect size \\
\hline 1975 & 117.96 & 12 & 0.00 & 0.27 \\
1995 & 128.19 & 12 & 0.00 & 0.19 \\
2015 & 111.56 & 12 & 0.00 & 0.17 \\
\hline
\end{tabular}

\subsubsection{Stating One's Original Contribution to the Field by Stating Results and Findings}

It is the most powerful rhetorical function of self-mention in that it explicitly shows the author's contributions to the academic field. This function is mainly used in results and discussion sections. It is also the most face-threatening and it reflects author's strong confidence. In the current corpus, the sentence which states one's original contribution often contains verbs such as demonstrate, show, discover, provide and so on. This distinguished feature is of great help in the classification of self-mention expressions because the first and the second rhetorical functions are similar. In example (5), the verb "provide" after "our results" explicitly accentuates the contribution of one's study, so this occurrence of self-mention belongs to the first rather than the second rhetorical function.

5) Our results provide support for the hypothesis that L1 vocabulary is positively associated with L2 listening comprehension success.

The result reveals that the overall frequency of this function per 10,000 words in the four disciplines has increased by $68 \%$ in 1995 and then dropped slightly by $8 \%$ in 2015. As for the diachronic changes in each discipline, except for applied linguistics, the other three disciplines have all witnessed increasing frequency of this function, among which the growth in biochemistry \& molecular biology is the most considerable. The diachronic change indicates that writers in sociology, 
electronic engineering and biochemistry \& molecular biology have a strong tendency to explicitly foreground their roles and claim responsibility for the research findings. In sharp contrast, scholars in applied linguistics have become more and more modest in displaying their research findings and academic contributions (52\% drop over the period).

\subsubsection{Elaborating an Argument, Presenting an Opinion, or Stating Knowledge}

Mental process of the authors is involved in this function. It conveys high degree of authorial visibility. Compared with the first function, this one is relatively more subjective because it contains more authors' personal opinions. This function often appears in discussion and conclusion sections. Verbs such as assume, argue, consider and conjecture frequently co-occur with personal pronouns when the authors intend to present their own argument and opinions. For example,

6) Thus, the ARF nucleotide exchange factor must be present on the ER membrane, and we argue that it is there to serve a role in some form of anterograde transport mediated by COPI.

(BMB, 1995)

The overall trends of change in the employment of this function are significantly different between soft and hard sciences. In soft sciences, an overall decline in frequency can be observed (53\% and 5\% drop respectively in applied linguistics and sociology). Although in sociology the frequency is the highest in 1995, which is 9.75 per 10,000 words, it still shows a downward trend in 2015. However, in hard disciplines, the frequencies have grown considerably, especially in biochemistry \& molecular biology. Therefore, we can come to the conclusion that writers in the hard sciences have become more active in promoting themselves and expressing their personal opinions over this period from 1975 to 2015 , while the opposite case can be seen in soft sciences.

\subsubsection{Describing or Explaining a Research Decision or Procedure}

This rhetorical function is mainly used to guide the readers by describing or recounting general methodology or specific procedures of research articles. As can be seen from (7), the personal pronoun "we" performs the function of telling the detailed information of the research.

7) To do so, we collected field and survey data from a total sample of students attending seven such schools.

As indicated by Table 4, Figures 2-4, we can find that authors in each discipline deploy self-mention which performs the rhetorical function of describing a research decision or procedure most frequently. It again highlights the significance of clearly presenting the methodological approach of a study (Hyland, 2002). Compared with authors in other disciplines, electronic engineers show a fairly more frequent use of this function during the period. This predominant use suggests that scholars in this field tend to be more systematic and meticulous 
in showing their professional credentials.

As for the diachronic changes, the overall frequency of this function in all four disciplines per 10,000 words has increased by $140 \%$ in 1995 and then fallen by $3 \%$ in 2015. This trend indicates that authors' awareness in stressing their familiarity with the methodological approach and gaining reader's trust by specifying the research process in detail has been heightened dramatically both in the hard and soft knowledge fields. Apart from applied linguistics, other three disciplines have all witnessed a steady increase of this rhetorical function, suggesting that authors in these three fields have taken some steps towards greater reader-visibility in research procedures.

\subsubsection{Stating a Purpose, Intention or Focus}

As is noted by Walková (2019), this function includes both intratextual organization and intertextual references. The former refers to the functions of showing the focus or intention of previous sections (example (8)) and following sections (example (9)). The latter includes self-mentions which quote one's own previous research (example (10)) and introduce future research direction or focus (example (11)).

8) So far, we have focused primarily on models from manufacturing applications.

9) In Section III, we will describe its reduction to solving equations over languages.

10) In our previous work, Kantaros, Thanou, and Tzes (2014), a control law for the distributed coverage of a non-convex environment is introduced, assuming a homogeneous group of robots equipped with range-limited, visibility-based sensors.

(EE, 2015)

11) We ourselves plan to explore this issue in more detail by examining how accent and intelligibility are related to other variables, such as processing time and subjective listener reactions to nonnative pronunciation.

The frequency per 10,000 words in the corpus shows an upward trend in all disciplines (details given in Table 4). With regard to the frequency in each discipline, we can find that disciplines differ in how their use of self-mention has changed. Applied linguistics undergoes $85 \%$ overall decrease in the frequency of this function during the period. Nevertheless, this dramatic decline is not evenly distributed across the four disciplines studied but is confined to applied linguistics. It indicates applied linguists' increasing awareness of personal attrition in describing the purpose, intention or focus of their studies.

\subsubsection{Acknowledging Other Researchers}

There is no doubt that the acknowledgements section is a prime site for this function. Other than acknowledging other scholars and stressing the contribu- 
tions of other scholars' to the study (example (12)), it also contains the functions of passing on the future research agenda to other researchers (example (13)) and preventing harm done to other researchers (example (14)). However, it should be noted that in Walková's model, this function also appears in other parts of a research article. For instance, example (12) is in the discussions section.

12) We should like to thank Dr J. A. Jackson for helpful suggestions and ideas.

(BMB, 1995)

13) Thus, we urge future research to attend to indirect as well as direct effects of parental imprisonment.

14) Any errors are my responsibility.

From Table 4, Figures 2-4, we can see that in all of the four disciplines at each time point, the function of acknowledging others is the least frequent. The same result can be found in Walková's research. Its infrequency can be accounted for by the fact that this function mainly appears in the acknowledgements section. It is also obvious that the change in the overall frequency of this function over time is very slight, which indicates that there has been little changes in the academic genres over the 40 years.

Although the overall frequency of the five rhetorical functions in electronic engineering outnumbers other three disciplines, as is suggested by the statistics, the frequency of acknowledging others in this field is approximately the lowest compared with other disciplines. It may suggest that scholars in this field tend not to convey high author visibility while interacting with other scholars in the academic community.

\section{Conclusion}

The main objective of the present study is to see the diachronic changes and cross-disciplinary differences in the frequency of self-mention and its rhetorical functions in academic texts over the 40 years (1975-2015). On the whole, the principal findings of this study can be summarized as follows:

Firstly, except for applied linguistics, the other three disciplines have all witnessed a considerable increase in the frequency of self-mention personal pronouns over the period and this trend is most obvious in biochemistry \& molecular biology. It suggests that making a clear individual contribution is increasingly encouraged in these fields and writers have thus become more positive in conveying their personal involvement in research process.

Secondly, the chi-square analysis reveals that there is significant interdisciplinary difference in the use of rhetorical functions of self-mentions. The frequency of the function of stating one's original contribution to the field increases steadily in biochemistry \& molecular biology, electronic engineering and sociology, which suggests that writers in these disciplines have become increasingly confident in overtly showing their contributions and making clear their novel ideas and originality. The similar result can be found in the third and fourth function, 
which shows writers' growing awareness in making clear the research process and approach for the targeted readers in these fields. As for the second function, the frequency increases in hard disciplines but falls in soft disciplines. The last rhetorical function is the least frequent among the five functions. The diachronic change and interdisciplinary differences shown in this function are also the least obvious.

The above findings pinpoint that the norms and conventions in academic writing are likely to develop in parallel with the development of disciplinary knowledge and the change of time. Therefore, the topic of self-mention deserves special attention and further investigation in order to provide accurate information about the strategic use of personal pronouns and their rhetorical functions in academic writing.

\section{Limitations and Implications}

The present study has two principal limitations that are noteworthy. Firstly, the distinctions between some rhetorical functions are not very clear-cut, so the classification of self-mention markers is somewhat subjective. Therefore, there are probably some errors which are hard to avoid. In addition, the number of disciplines is relatively small, which makes it hard to apply the findings of the current study to other disciplines that have not been investigated. In this regard, future research could broaden the investigation by enlarging the number of disciplines.

As shown by the results, writers' employment of self-mention personal pronouns in the four disciplines has increased significantly over time. It has important pedagogical implications in terms of academic writing instruction. It is necessary for instructors to teach their students the significance of authorial presence and the way to appropriately show themselves in academic writing. Additionally, the analysis of rhetorical functions indicates that writers in different disciplines tend to present themselves in differing ways. Hence, instructors are supposed to grasp the features of their disciplines and teach students corresponding writing strategies in an appropriate way. Moreover, the present study also suggests some research implications. A promising direction for future studies appears to be the exploration of interdisciplinary differences in the use of these five rhetorical functions in student corpus. By doing this, we can have a better understanding of how students of different majors exploit these functions and then offer useful suggestions for teaching academic writing.

\section{Acknowledgements}

The author extends her sincere gratitude to Professor Li Li for her very helpful comments on the draft of this manuscript.

\section{Conflicts of Interest}

The author declares no conflicts of interest regarding the publication of this paper. 


\section{References}

Anthony, L. (2017). AntFileConverter (Version 1.2.1) [Computer Software]. Tokyo, Japan: Waseda University. https://www.laurenceanthony.net/software

Anthony, L. (2019). AntConc (Version 3.5.8) [Computer Software]. Tokyo, Japan: Waseda University. https://www.laurenceanthony.net/software

Arnaudet, M. L., \& Barrett, M. E. (1984). Approaches to Academic Reading and Writing. Hoboken, NJ: Prentice-Hall.

Becher, T. (1989). Academic Tribes and Territories: Intellectual Enquiry and the Cultures of the Disciplines. Milton Keynes: Open University Press.

Dontcheva-Navrátilová, O. (2013). Authorial Presence in Academic Discourse: Functions of Author-Reference Pronouns. Linguistica Pragensia, 23, 9-30.

Dueñas, P. M. (2007). “I/We Focus on ...”: A Cross-Cultural Analysis of Self-Mentions in Business Management Research Articles. Journal of English for Academic Purposes, 6, 143-162. https://doi.org/10.1016/j.jeap.2007.05.002

Fairclough, N. (1992). Discourse and Social Change (Vol. 10). Cambridge: Polity Press.

Harwood, N. (2005). "Nowhere Has Anyone Attempted ... In This Article I Aim to Do Just That": A Corpus-Based Study of Self-Promotional I and We in Academic Writing across Four Disciplines. Journal of Pragmatics, 37, 1207-1231. https://doi.org/10.1016/j.pragma.2005.01.012

Hyland, K. (2001). Humble Servants of the Discipline? Self-Mention in Research Articles. English for Specific Purposes, 20, 207-226. https://doi.org/10.1016/S0889-4906(00)00012-0

Hyland, K. (2002). Authority and Invisibility: Authorial Identity in Academic Writing. Journal of Pragmatics, 34, 1091-1112. https://doi.org/10.1016/S0378-2166(02)00035-8

Hyland, K. (2008). Disciplinary Voices: Interactions in Research Writing. English Text Construction, 1, 5-22. https://doi.org/10.1075/etc.1.1.03hyl

Hyland, K., \& Jiang, F. K. (2018). In This Paper We Suggest: Changing Patterns of Disciplinary Metadiscourse. English for Specific Purposes, 51, 18-30.

https://doi.org/10.1016/j.esp.2018.02.001

Ivanič, R. (1998). Writing and Identity: The Discoursal Construction of Identity in Academic Writing. Amsterdam: John Benjamins Publishing. https://doi.org/10.1075/swll.5

Ivanič, R., \& Camps, D. (2001). I Am How I Sound: Voice as Self-Representation in L2 Writing. Journal of Second Language Writing, 10, 3-33.

https://doi.org/10.1016/S1060-3743(01)00034-0

Kuo, C. H. (1999). The Use of Personal Pronouns: Role Relationships in Scientific Journal Articles. English for Specific Purposes, 18, 121-138. https://doi.org/10.1016/S0889-4906(97)00058-6

Lachowicz, D. (1981). On the Use of the Passive Voice for Objectivity, Author Responsibility and Hedging in EST. Science of Science, 2, 105-115.

Lee, T. K. (2013). Author Manifestation and Perceptions of Self in Chinese Academic Discourse: Comparisons with English. Languages in Contrast, 13, 90-112. https://doi.org/10.1075/lic.13.1.05lee

Li, N., \& Lee, T. K. (2013). Authorial Voice in Academic Writing: A Contrastive Perspective. Journal of PLA University of Foreign Languages, 36, 17-23+40+127. (In Chinese)

Luzon, M. J. (2009). The Use of "We" in a Learner Corpus of Reports Written by EFL Engineering Students. Journal of English for Academic Purposes, 8, 192-206.

https://doi.org/10.1016/j.jeap.2009.04.001 
Martinez, I. A. (2005). Native and Non-Native Writers' Use of First Person Pronouns in the Different Sections of Biology Research Articles in English. Journal of Second Language Writing, 14, 174-190. https://doi.org/10.1016/j.jslw.2005.06.001

Mirzapour, F. (2016). Gender Differences in the Use of Hedges and First Person Pronouns in Research Articles of Applied Linguistics and Chemistry. International Journal of Applied Linguistics and English Literature, 5, 166-173.

https://doi.org/10.7575/aiac.ijalel.v.5n.6p.166

Tang, R., \& John, S. (1999). The "I'in Identity: Exploring Writer Identity in Student Academic Writing through the First Person Pronoun". English for Specific Purposes, 18, S23-S39. https://doi.org/10.1016/S0889-4906(99)00009-5

Vladimirou, D. (2007). I Suggest That We Need More Research: Personal Reference in Linguistics Journal Articles. In C. Gabrielatos, R. Slesser, \& J. Unger (Eds.), Lancaster University Postgraduate Conference in Linguistics and Language Teaching (pp. 139-157). Lancaster, U.K.: Lancaster University Department of Linguistics and English Language.

Walková, M. (2019). A Three-Dimensional Model of Personal Self-Mention in Research Papers. English for Specific Purposes, 53, 60-73.

https://doi.org/10.1016/j.esp.2018.09.003

Wu, G. (2010). Identity Construction in English and Chinese Research Articles: A Contrastive Study. Doctoral Dissertation, Shanghai: Shanghai International Studies University.

\section{Appendix: Journal List}

\section{Applied linguistics}

Language Learning

Modern Language Journal

Foreign Language Annals

Sociology

Annual Review of Sociology

Sociological Methods \& Research

Work and Occupations

Electronic engineering

Proceedings of the IEEE

Automatica

IEEE Transactions on Automatic Control

Biochemistry \& Molecular Biology

Cell

Annual Review of Biochemistry

Nucleic Acids Research 